\title{
Effect of tablets with a combination of telmisartan and amlodipine on patients with hypertension: the Cotalo study
}

\begin{abstract}
Mitsuru Ohishi ${ }^{1}$, Tatsuo Kawai ${ }^{1}$, Norihiro Hayashi ${ }^{2}$, Shoichi Kitano ${ }^{3}$, Tomohiro Katsuya ${ }^{4}$, Masahiro Nagano ${ }^{5}$, Atsushi Hirotani ${ }^{6}$, Koichi Yamamoto ${ }^{1}$, Kei Kamide ${ }^{1}$ and Hiromi Rakugi ${ }^{1}$

Fixed-dose combination (FDC) therapy with telmisartan $40 \mathrm{mg}+$ amlodipine $5 \mathrm{mg}$ (T40/A5) is expected to achieve tight blood pressure (BP) control because of the strong efficacy and long half-life of each drug. The aims of this study were to evaluate the 24-h antihypertensive efficacy of T40/A5 FDC therapy and to explore differences that may arise owing to different administration times in Japanese patients whose hypertension was not controlled by $5 \mathrm{mg}$ of amlodipine per day. In this randomized clinical trial, 44 patients who had been taking amlodipine $5 \mathrm{mg}$ per day and did not achieve their optimal BP target were enrolled (mean age: $67.8 \pm 10.2$ years). The subjects were then randomly assigned to a T40/A5 morning or evening administration group (22 patients per group). At baseline and 8 weeks after randomization, we evaluated clinical BP and various laboratory values and performed ambulatory BP monitoring (ABPM). Clinical and mean BP evaluated with ABPM at 8 weeks ( $24 \mathrm{~h}$, daytime, nighttime and early morning) were significantly decreased compared with BP at baseline. There were no significant differences in the diurnal BP profile change from baseline to 8 weeks between subjects in the morning and evening administration groups. There were also no significant differences in the diurnal BP profile change from baseline to 8 weeks between subjects with or without metabolic syndrome. We conclude that T40/A5 FDC therapy significantly decreased the 24-h mean and clinical BP, independent of administration time, in patients whose hypertension was not controlled by $5 \mathrm{mg}$ of amlodipine.

Hypertension Research (2013) 36, 620-626; doi:10.1038/hr.2013.10; published online 21 February 2013
\end{abstract}

Keywords: ambulatory blood pressure monitoring; amlodipine; fixed-dose combination; metabolic syndrome; telmisartan

\section{INTRODUCTION}

Angiotensin II receptor blockers (ARBs) are effective and welltolerated antihypertensive agents that inhibit aldosterone production, vasoconstriction and sodium retention by blocking the reninangiotensin-aldosterone system. ${ }^{1-3}$ Telmisartan is a highly selective ARB for the AT1 receptor and, as the elimination half-life of this agent is $\sim 24 \mathrm{~h}$, once-daily administration of telmisartan is reported to reduce blood pressure (BP) for an entire $24 \mathrm{~h} .{ }^{4,5}$ Amlodipine, a calcium channel blocker (CCB), is another highly effective and longacting antihypertensive agent that is widely used for hypertension treatment. $^{6}$

The current guidelines indicate that treatment with two or more antihypertensive agents is necessary to achieve optimal BP for most hypertensive patients in order to reduce cardiovascular risk. ${ }^{1,2}$ Moreover, the Anglo-Scandinavian Cardiac Outcomes Trials Blood Pressure Lowering Arm (ASCOT-BPLA) ${ }^{7}$ and Cardiovascular Events through Combination Therapy in Patients Living with Systolic Hypertension (ACCOMPLISH) ${ }^{8}$ revealed the clinical benefits of combination therapy with renin-angiotensin-aldosterone system blockade and CCB.

Currently, a single-pill combination of ARB and CCB is available for once-daily administration to manage hypertension with better treatment adherence. ${ }^{9,10}$ Telmisartan $40 \mathrm{mg}+$ amlodipine $5 \mathrm{mg}$ (T40/A5) fixed-dose combination (FDC) therapy is expected to achieve tight $\mathrm{BP}$ control because of the strong efficacy and long half-life of each agent. ${ }^{11}$ However, to our knowledge, no studies have been conducted that employed ambulatory BP monitoring (ABPM) in Japanese hypertensive patients to show that T40/A5 FDC therapy has lasting BP-lowering efficacy. In addition, there are no data available regarding whether the administration time (morning or evening) of T40/A5 FDC influences its BP-lowering effects in Japanese patients who had uncontrolled hypertension while taking amlodipine. However, Hermida et al. ${ }^{12}$ reported that telmisartan monotherapy with bedtime administration could achieve significantly better nocturnal BP regulation compared with morning administration. The aims of this study were (1) to evaluate the 24 -h efficacy of

${ }^{1}$ Department of Geriatric Medicine and Nephrology, Osaka University Graduate School of Medicine, Osaka, Japan; ${ }^{2}$ Wada Hospital, Osaka, Japan; ${ }^{3}$ Nanko Clinic, Osaka, Japan; ${ }^{4}$ Katsuya Clinic, Hyogo, Japan; ${ }^{5}$ Nagano Clinic, Osaka, Japan and ${ }^{6}$ Hirotani Clinic, Osaka, Japan

Correspondence: Dr M Ohishi, Department of Geriatric Medicine and Nephrology, Osaka University Graduate School of Medicine, 2-2 Yamadaoka (B6), Osaka 565-0871, Japan. E-mail: ohishi@geriat.med.osaka-u.ac.jp

Received 13 November 2012; revised 3 December 2012; accepted 16 December 2012; published online 21 February 2013 
T40/A5 FDC therapy in the control of hypertension by performing ABPM on the participants and (2) to conduct a preliminary investigation of differences owing to administration time in Japanese patients whose hypertension was not controlled by $5 \mathrm{mg}$ of amlodipine per day.

\section{METHODS}

\section{Study subjects and study design}

Figure 1 shows the study design. In this randomized clinical trial, we initially recruited patients who had been taking $5 \mathrm{mg}$ of amlodipine/day for $>4$ weeks. Written informed consent was obtained from all of the participants. Patients taking other CCBs or ARBs were excluded, and there was no change to the other antihypertensive agents throughout the observation period. After a screening period of $>2$ weeks, subjects with a clinical systolic BP (SBP) of $\geqslant 140 \mathrm{~mm} \mathrm{Hg}$, a clinical diastolic BP (DBP) of $\geqslant 90 \mathrm{~mm} \mathrm{Hg}$, or both were enrolled in this study. We then switched the patients from $5 \mathrm{mg}$ of amlodipine per day to T40/A5 FDC therapy. The subjects were randomly assigned to either a morning $(n=22)$ or an evening $(n=22)$ administration group. At baseline and 8 weeks after randomization, we evaluated the clinical BP, АBPM and various laboratory values.

We assessed changes from baseline in the $24 \mathrm{~h}$, daytime, nighttime and early morning BP after 8 weeks of treatment and changes from baseline in the clinical BP and laboratory values after 8 weeks of treatment. We also performed comparisons of the above assessments between the morning and evening administration groups. The Clinical Investigations Ethics Committee of Osaka University Hospital approved the study protocol. The study was performed in adherence with the principles of the Declaration of Helsinki and according to Good Clinical Practice standards.

\section{BP measurements}

Conventional BP was measured by trained observers with an electronic sphygmomanometer. Following guidelines for the management of hypertension, clinical BP was measured at least two times in a sitting position after $5 \mathrm{~min}$ of rest, and we adopted the average of two readings as the clinical BP if the difference in measured values was $<5 \mathrm{~mm} \mathrm{Hg}$. When the difference in measured values was $\geqslant 5 \mathrm{~mm} \mathrm{Hg}$, additional measurements were conducted to obtain stable BP readings and we adopted the average of the two stable readings as the clinical $\mathrm{BP}$.

\section{Ambulatory BP monitoring}

Ambulatory BP was evaluated with portable monitors (FB-270 device; Fukuda Denshi Co. Ltd., Tokyo, Japan) at 30-min intervals from 0600 to 2300 hours and at 60 -min intervals from 2300 to 0600 hours. From the ABPM value, we calculated the 24-h mean BP, daytime (0900 to 2100 hours) mean BP, nighttime (0100 to 0600 hours) mean $\mathrm{BP}$, and early morning ( $2 \mathrm{~h}$ after rising) mean $\mathrm{BP}^{13}$

\section{Clinical evaluations}

The estimated glomerular filtration ratio (eGFR) was calculated with the following equation: eGFR $\left(\mathrm{ml} \mathrm{min}^{-1} 1.73 \mathrm{~m}^{-2}\right)=194 \times$ creatinine $^{-1.094} \times$ age $^{-0.287}$ $(\times 0.739$ if female $) .{ }^{14}$ Patients with diabetes mellitus were diagnosed according to the diagnostic criteria of the American Diabetes Association: fasting plasma glucose $(\mathrm{FPG}) \geqslant 126 \mathrm{mg} \mathrm{dl}^{-1}, \mathrm{HbAlc} \geqslant 6.5 \%$, 2-h value in oral glucose tolerance test $\geqslant 200 \mathrm{mg} \mathrm{dl}^{-1}$, random plasma glucose concentration $\geqslant 200 \mathrm{mg} \mathrm{dl}^{-1}$ in the presence of symptoms, or taking drugs for diabetes. Patients with considered to have hyperlipidemia if total cholesterol was $\geqslant 220 \mathrm{mg} \mathrm{dl}^{-1}$, low-density lipoprotein cholesterol was $\geqslant 140 \mathrm{mg} \mathrm{dl}^{-1}$, triglycerides were $\geqslant 150 \mathrm{mg} \mathrm{dl}^{-1}$, or they were taking drugs for hyperlipidemia. We evaluated insulin resistance by means of the HOMA-R (homeostasis model assessment ratio), which was calculated with the following equation: HOMA-R $=\mathrm{FPG} \times$ fasting plasma insulin/405.

Metabolic syndrome was defined as the presence of two or more of the following abnormalities in addition to abnormally high waist circumference ( $\geqslant 85 \mathrm{~cm}$ for men and $\geqslant 90 \mathrm{~cm}$ for women): (1) triglycerides $\geqslant 150 \mathrm{mg} \mathrm{dl}^{-1}$ and/or high-density lipoprotein cholesterol $<40 \mathrm{mg} \mathrm{dl}^{-1}$ or under treatment for dyslipidemia, (2) SBP $\geqslant 130 \mathrm{~mm} \mathrm{Hg}$ and/or DBP $\geqslant 85 \mathrm{~mm} \mathrm{Hg}$ or under treatment for hypertension, and (3) FPG $\geqslant 110 \mathrm{mg} \mathrm{dl}^{-1}$ or under treatment for diabetes mellitus. ${ }^{15}$ Potential metabolic syndrome was also defined as one of above abnormalities in addition to BMI $\geqslant 25$.

\section{Statistical analysis}

Data were analyzed with SAS 9.3 (SAS, Cary, NC, USA) and are presented as the mean \pm s.d. Differences in patient characteristics and laboratory test results between the groups were analyzed with Fisher's exact test and two-sample $t$-test. Differences in the clinical BP, clinical heart rate and ABPM values between the groups were analyzed with analysis of covariance. A value of $P<0.05$ was regarded as significant.

\section{RESULTS}

Table 1 lists the baseline clinical characteristics of the participants in the present study. The mean age of the 44 subjects was $67.8 \pm 10.2$ years. Although the subjects in the morning administration group had significantly higher triglyceride levels $(193.5 \pm 145.1$ vs. $109.2 \pm$ $\left.59.0 \mathrm{mg} \mathrm{dl}^{-1}, \quad P=0.022\right)$ and significantly lower high-density lipoprotein cholesterol $\left(50.5 \pm 13.4\right.$ vs. $\left.72.9 \pm 21.5 \mathrm{mg} \mathrm{dl}^{-1}, P<0.001\right)$ than subjects in the evening administration group, there were no significant differences in the other characteristics between the two groups.

First, we analyzed the BP profile of the study subjects. Figure 2 shows a comparison of the 24-h BP profile for ABPM at baseline and at 8 weeks. The mean SBP at 8 weeks was significantly decreased compared with the mean SBP at baseline (121.8 \pm 13.2 vs. $130.5 \pm$ $11.4,125.6 \pm 13.2$ vs. $134.4 \pm 11.2,116.1 \pm 16.2$ vs. $123.5 \pm 13.6$, and $127.4 \pm 14.5$ vs. $135.2 \pm 12.0 \mathrm{~mm} \mathrm{Hg}$ for $24 \mathrm{~h}$, daytime, nighttime and early morning, respectively) (Table 2). The mean DBP at 8 weeks was also significantly decreased compared with the mean DBP at baseline (74.8 \pm 9.3 vs. $80.3 \pm 10.7,77.1 \pm 9.0$ vs. $83.0 \pm 10.1,69.5 \pm 11.0$ vs. $75.1 \pm 11.9$, and $78.7 \pm 9.8$ vs. $84.8 \pm 12.5 \mathrm{~mm} \mathrm{Hg}$ for $24 \mathrm{~h}$, daytime, nighttime and early morning, respectively) (Table 2 ). However, there

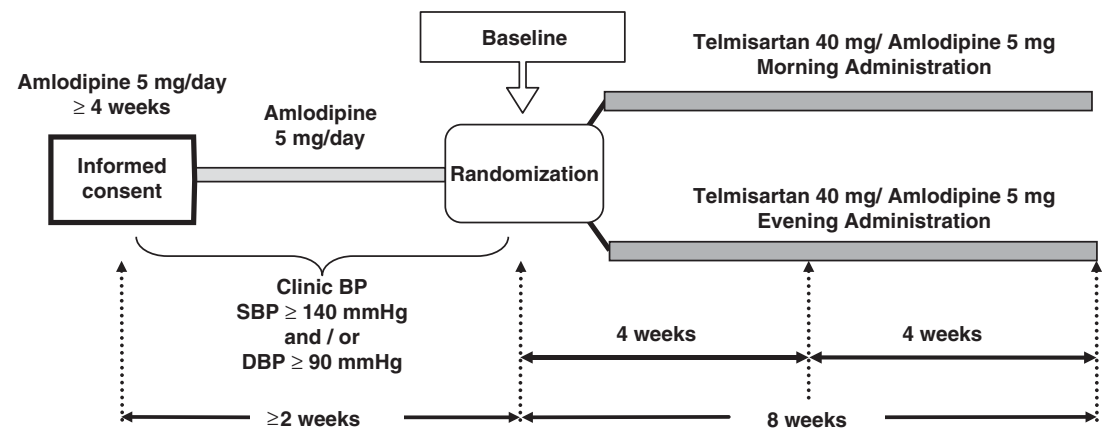

Figure 1 Study design. 
Table 1 Patient characteristics

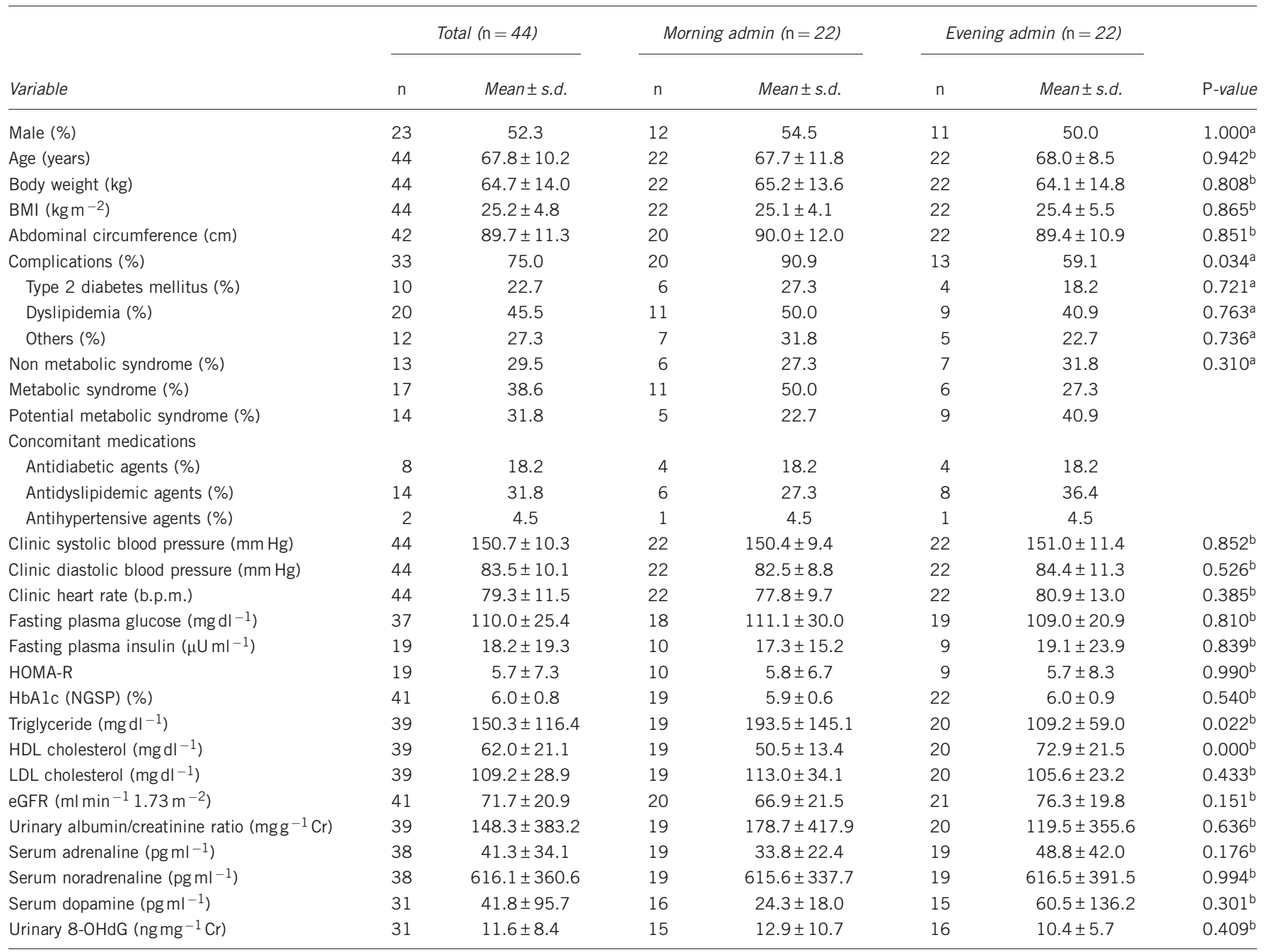

Abbreviations: BMI, body mass index; Cr, creatinine; eGFR, estimated glomerular filtration rate; HbAlc, hemoglobin Alc; HDL, high-density lipoprotein; HOMA-R, homeo- stasis model insulin resistance; LDL, low-density lipoprotein; NGSP, national glycohemoglobin standardization program; 8-OHdG, 8-hydroxy-20-deoxyguanosine.

aFisher's exact test.

b2-sample $t$-test.

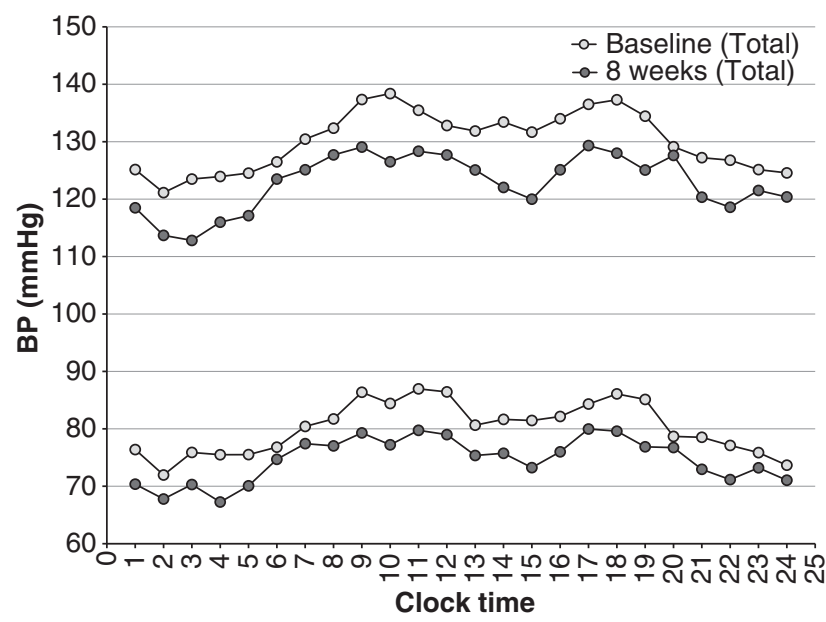

Figure 2 Twenty-four-hour profile of mean hourly blood pressure: baseline (gray) and 8 weeks (black). were no significant differences in the mean BP change $(24 \mathrm{~h}$, daytime, nighttime and early morning) from baseline to 8 weeks between the subjects in the morning and evening administration groups (Table 2). Similarly, the clinical BP at 8 weeks was significantly diminished compared with the clinical BP at baseline (SBP: $135.7 \pm 15.0$ vs. 150.2 \pm 10.4 DBP: $75.0 \pm 10.0$ vs. $83.0 \pm 10.2 \mathrm{~mm} \mathrm{Hg}$ ). However, there was no significant difference in the change in clinical BP from baseline to 8 weeks between subjects in the morning and evening administration groups (Table 3). In addition, the time at which T40/A5 FDC therapy was administered (morning or evening) did not appear to make a difference in the clinical heart rate (Table 3) or mean heart rate as evaluated by ABPM (data not shown). To further investigate, we analyzed the effect of T40/A5 FDC on dipper and non-dipper type hypertension in the subjects. The mean nighttime BP at 8 weeks in subjects with dipper type hypertension did not significantly decrease compared with the mean $\mathrm{BP}$ at baseline and showed no excessive $\mathrm{BP}$ lowering; however, the daytime BP at 8 weeks in subjects with dipper type hypertension, and both the daytime and nighttime BP at 8 weeks in subjects with non-dipper type hypertension, was significantly 


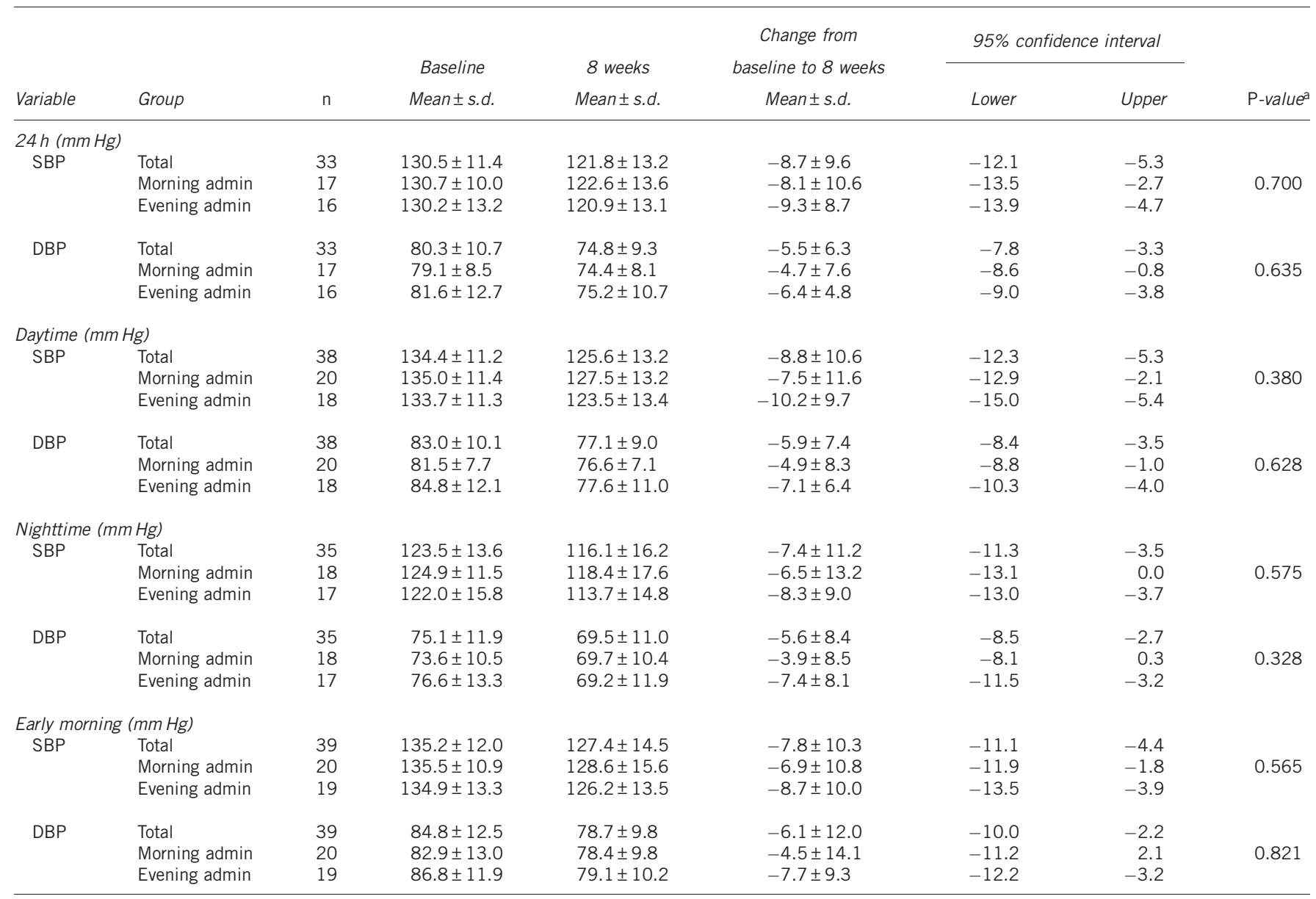

Abbreviations: ABPM, ambulatory BP monitoring; DBP, diastolic blood pressure; SBP, systolic blood pressure.

aAnalysis of covariance (ANCOVA).

Table 3 Clinic blood pressure and clinic heart rate

\begin{tabular}{|c|c|c|c|c|c|c|c|c|}
\hline \multirow[b]{2}{*}{ Variable } & \multirow[b]{2}{*}{ Group } & \multirow[b]{2}{*}{$\mathrm{n}$} & \multirow{2}{*}{$\begin{array}{c}\text { Baseline } \\
\text { Mean } \pm \text { s.d. }\end{array}$} & \multirow{2}{*}{$\begin{array}{c}8 \text { weeks } \\
\text { Mean } \pm \text { s.d. }\end{array}$} & \multirow{2}{*}{$\begin{array}{c}\text { Change from } \\
\text { baseline to } 8 \text { weeks } \\
\text { Mean } \pm \text { s.d. }\end{array}$} & \multicolumn{2}{|c|}{ 95\% confidence interval } & \multirow[b]{2}{*}{$\mathrm{P}$-value } \\
\hline & & & & & & Lower & Upper & \\
\hline \multicolumn{9}{|c|}{ Clinic blood pressure $(\mathrm{mm} \mathrm{Hg})$} \\
\hline \multirow[t]{3}{*}{ SBP } & Total & 40 & $150.2 \pm 10.4$ & $135.7 \pm 15.0$ & $-14.4 \pm 12.7$ & -18.5 & -10.4 & \multirow{3}{*}{0.630} \\
\hline & Morning admin & 21 & $149.9 \pm 9.3$ & $134.6 \pm 13.5$ & $-15.3 \pm 11.2$ & -20.4 & -10.2 & \\
\hline & Evening admin & 19 & $150.5 \pm 11.8$ & $137.1 \pm 16.9$ & $-13.5 \pm 14.5$ & -20.4 & -6.5 & \\
\hline \multirow[t]{3}{*}{ DBP } & Total & 40 & $83.0 \pm 10.2$ & $75.0 \pm 10.0$ & $-8.0 \pm 8.1$ & -10.6 & -5.4 & \multirow{3}{*}{0.902} \\
\hline & Morning admin & 21 & $82.6 \pm 9.0$ & $74.6 \pm 8.2$ & $-8.0 \pm 8.6$ & -11.9 & -4.1 & \\
\hline & Evening admin & 19 & $83.5 \pm 11.6$ & $75.5 \pm 11.9$ & $-8.0 \pm 7.8$ & -11.8 & -4.3 & \\
\hline \multicolumn{9}{|c|}{ Clinic heart rate (b.p.m.) } \\
\hline & Total & 40 & $78.5 \pm 11.1$ & $77.3 \pm 13.5$ & $-1.2 \pm 9.2$ & -4.2 & 1.8 & \multirow{3}{*}{0.546} \\
\hline & Morning admin & 21 & $77.2 \pm 9.6$ & $75.3 \pm 10.2$ & $-1.9 \pm 7.4$ & -5.3 & 1.5 & \\
\hline & Evening admin & 19 & $79.9 \pm 12.8$ & $79.5 \pm 16.4$ & $-0.4 \pm 11.1$ & -5.8 & 4.9 & \\
\hline
\end{tabular}

Abbreviations: DBP, diastolic blood pressure; SBP, systolic blood pressure.

${ }^{\mathrm{a}}$ Analysis of covariance (ANCOVA).

decreased compared with the mean SBP at baseline. In our subjects, $18.2 \%$ changed from non-dipper to dipper type hypertension, $12.1 \%$ changed from dipper to non-dipper type hypertension, $30.3 \%$ remained in dipper type hypertension and $39.4 \%$ remained in nondipper type hypertension. There were no significant differences between the subjects in the morning and evening administration groups $(P=0.345)$.
Table 4 contains comparisons of the laboratory test values measured at baseline and after 8 weeks of treatment. There were no significant changes in FPG, HOMA-R, HbAlc, triglyceride, highdensity lipoprotein cholesterol, low-density lipoprotein cholesterol, eGFR, urinary albumin/creatinine ratio, serum noradrenaline, serum dopamine and urinary $8-\mathrm{OHdG}$ in all subjects, subjects in the morning administration group or subjects in the evening 
Table 4 Laboratory test

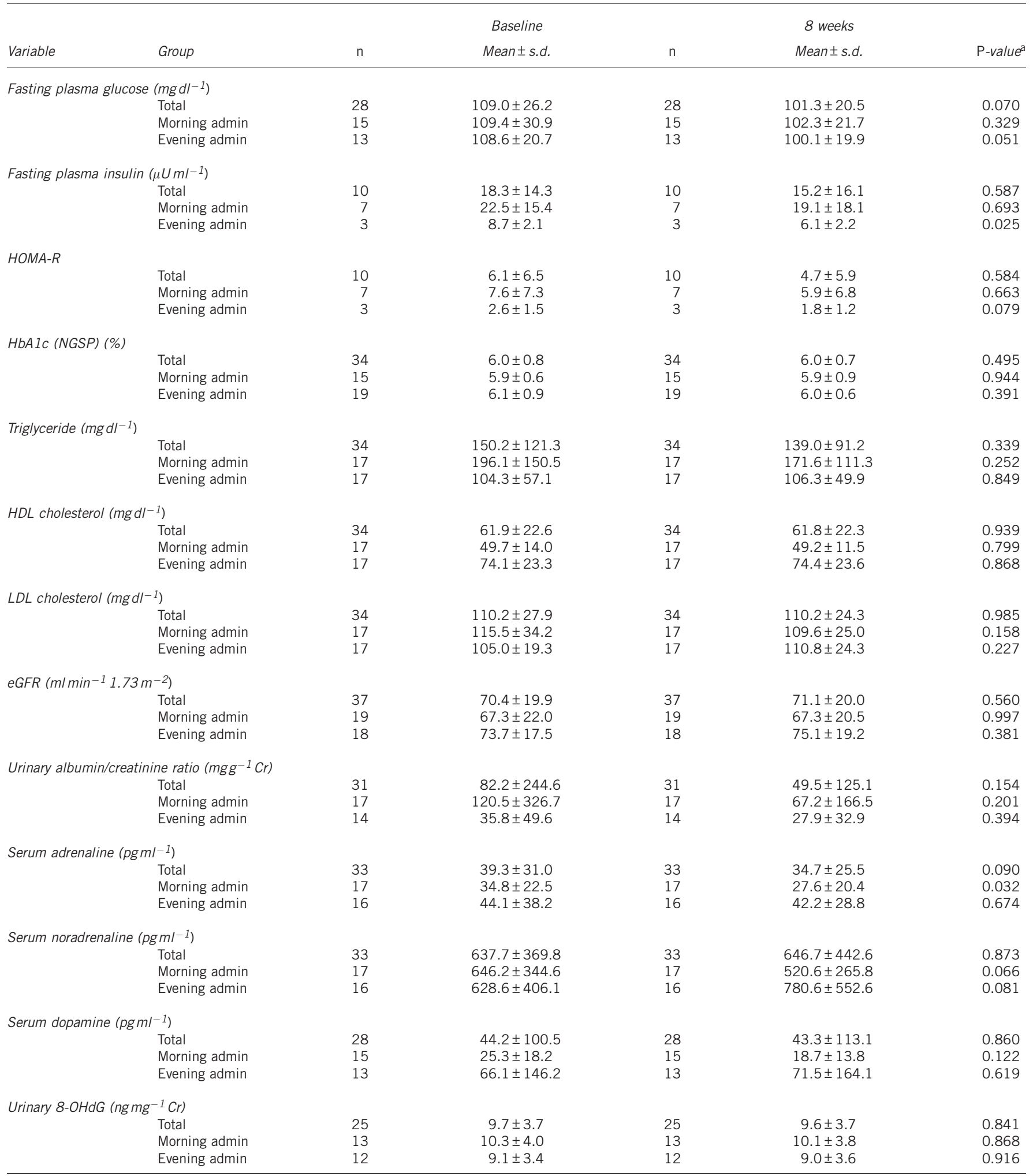

Abbreviations: Cr, creatinine; eGFR, estimated glomerular filtration rate; HbA1c, hemoglobin Alc; HDL, high-density lipoprotein; HDL, high-density lipoprotein; HOMA-R, homeo- stasis model insulin resistance; LDL, low-density lipoprotein; NGSP, national glycohemoglobin standardization program; 8-OHdG, 8-hydroxy-20-deoxyguanosine.

analysis of covariance (ANCOVA). 
Table 5 ABPM Value (compared between subjects with and without metabolic syndrome)

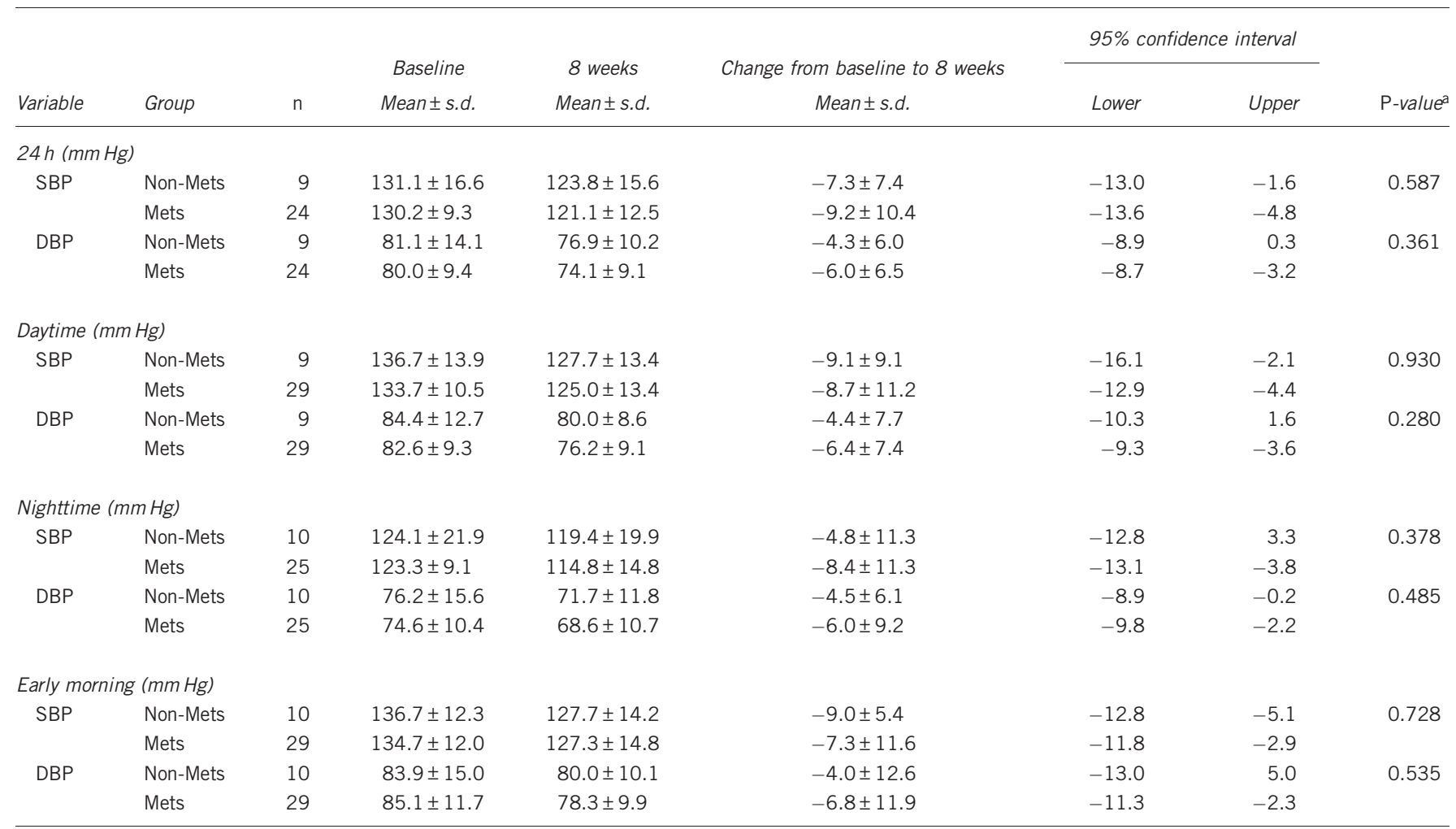

Abbreviations: ABPM, ambulatory BP monitoring; DBP, diastolic blood pressure; Mets, metabolic syndrome; SBP, systolic blood pressure.

${ }^{a}$ Analysis of covariance (ANCOVA).

administration group. However, subjects in the morning administration group had significantly lower serum adrenaline levels $(27.6 \pm 20.4$ vs. $\left.34.8 \pm 22.5 \mathrm{mg} \mathrm{dl}^{-1}, \quad P=0.032\right)$ and subjects in the evening administration group had significantly lower fasting plasma insulin level $\left(6.1 \pm 2.2\right.$ vs. $\left.8.7 \pm 2.2 \mathrm{mg} \mathrm{dl}^{-1}, P=0.025\right)$ at 8 weeks compared with baseline.

Finally, we compared BP profiles between subjects with or without metabolic syndrome or potential metabolic syndrome. There was no significant difference in the mean BP change $(24 \mathrm{~h}$, daytime, nighttime and early morning) from baseline to 8 weeks between subjects with or without metabolic syndrome (Table 5).

\section{DISCUSSION}

Although telmisartan is known to have long-lasting effects on lowering BP, previous reports have suggested that high-dose ( $80 \mathrm{mg}$ per day) telmisartan monotherapy administered at bedtime may achieve significantly better nocturnal BP regulation than morning administration. ${ }^{12}$ Previous reports have shown that drug adherence rates are generally higher for morning administration than for evening administration. ${ }^{16}$ Although the present study was conducted in a university medical hospital and subjects showed good adherence to drug administration, such differences in adherence rate could influence the observed effect of T40/A5 FDC on the patients' general clinical condition. In fact, in the present study we found that in patients whose hypertension was uncontrolled by $5 \mathrm{mg}$ of amlodipine per day, T40/A5 FDC therapy achieved optimal mean $\mathrm{BP}$ during the day and night regardless of the time of administration. We also revealed that both morning administration and evening administration of T40/A5 FDC could safely reduce BP equally in subjects with dipper type and non-dipper type hypertension. In addition to both telmisartan and amlodipine having strong efficacy and a long half-life, these two agents likely have complementary effects on reducing BP; telmisartan inhibits vasoconstriction caused by angiotensin II, while amlodipine leads to vasodilation by blocking the transmembrane calcium influx into vascular smooth muscle cells. The 24-h BP profile as measured by ABPM is known to correlate with the development of cardiovascular disease and prognosis more accurately than office $\mathrm{BP} ;{ }^{17-20}$ in addition, nighttime $\mathrm{BP}$ was recently shown to be a better predictor of outcome than other $\mathrm{BP}$ profiles evaluated by ABPM. ${ }^{21,22}$ Our study suggests that T40/A5 FDC therapy may prevent cardiovascular disease and improve prognosis independent of the time of administration.

The relationship between metabolic syndrome and diurnal BP changes remains controversial, although pooled data suggest that patients with metabolic syndrome are more likely to have a nondipping pattern in their 24 -h BP profile. ${ }^{23}$ Telmisartan is known to act as a partial agonist of peroxisome proliferator-activated receptor gamma, which regulates fatty acid storage and glucose metabolism, and it is reported to have positive effects on glucose and lipid metabolism. ${ }^{24,25}$ Therefore, we investigated the changes in glucose and lipid metabolism after 8 weeks of treatment withT40/A5 and found that there were no significant changes. We also investigated whether there were significant differences in the efficacy of T40/A5 FDC therapy between patients with and without metabolic syndrome and found that T40/A5 FDC therapy was associated with optimal BP in patients with and without metabolic syndrome with no significant differences.

Morning administration of T40/A5 was associated with a significant reduction in serum adrenaline from baseline values, but evening administration had no impact on serum adrenaline. CCB causes reflex activation of the sympathetic nervous system and increases 
catecholamine. ${ }^{26,27}$ On the other hand, activation of the AT1 receptor by angiotensin II could cause sympathetic overactivity 28,29 and, although the effects of ARBs on catecholamine secretion is still controversial, several studies have shown that renin-angiotensinaldosterone system blockade by ARBs could decrease the excess sympathetic responses to chronic stress and reduce serum catecholamine. ${ }^{30}$ The elimination half-life of telmisartan is $\sim 24 \mathrm{~h}$ and that of amlodipine is $30-50 \mathrm{~h} ;{ }^{4-6}$ as we drew blood samples from all of our patients in the daytime, it is possible that only when T40/A5 was administered in the morning were blood concentrations of telmisartan high enough to reduce serum catecholamine levels at the time of the blood draw. However, further investigations are needed to clarify the mechanisms of action of T40/A5 therapy.

The present study has several limitations. First, the sample size was relatively small and the follow-up period was relatively short; larger and longer studies could better reflect the clinical efficacy or impact on prognosis of T40/A5 FDC therapy. Second, several study subjects had already taken various orally administered drugs for dyslipidemia and diabetes mellitus at baseline; these agents might have affected several parameters, such as glucose levels and lipid profile. Third, although all blood samples were obtained during the daytime, the time of blood sampling varied (morning or afternoon); therefore, the circadian variation in catecholamine might have affected our results. Finally, more-frequent BP measurement (for example, 15-20-min intervals) or 48-h periods of ABPM might have revealed the clinical effects of T40/A5 FDC therapy on the diurnal BP profile more accurately.

In conclusion, we showed that combination therapy with $40 \mathrm{mg}$ of telmisartan and $5 \mathrm{mg}$ of amlodipine significantly decreased the 24-h mean BP and clinical BP in patients whose hypertension was uncontrolled by $5 \mathrm{mg}$ of amlodipine per day, independent of administration time (morning or evening).

\section{ACKNOWLEDGEMENTS}

This study was supported in part by grants-in-aid from The Waksman Foundation of Japan, Inc. (Tokyo, Japan).

1 Mansia G, De Backer G, Dominiczak A, Cifkova R, Fagard R, Germano G, Grassi G, Heagerty AM, Kjeldsen SE, Laurent S, Narkiewicz K, Ruilope L, Rynkiewicz A Schmieder RE, Struijker Boudier HA, Zanchetti AEuropean Society of Hypertension; European Society of Cardiology. 2007 ESH-ESC Guidelines for the management of arterial hypertension: the task force for the management of arterial hypertension of the European Society of Hypertension (ESH) and of the European Society of Cardiology (ESC). Blood Press 2007; 16: 135-232.

2 Chobanian AV, Bakris GL, Black HR, Cushman WC, Green LA, Izzo Jr JL, Jones DW, Materson BJ, Oparil S, Wright Jr JT, Roccella EJ. Joint National Committee on Prevention, Detection, Evaluation, and Treatment of High Blood Pressure. National Heart, Lung, and Blood Institute; National High Blood Pressure Education Program Coordinating Committee. Seventh report of the Joint National Committee on Prevention, Detection, Evaluation, and Treatment of High Blood Pressure. Hypertension 2003; 42: 1206-1252.

3 Sharpe M, Jarvis B, Goa KL. Telmisartan: a review of its use in hypertension. Drugs 2001; 61: 1501-1529.

4 Neutel JM, Smith DHG. Evaluation of angiotensin II receptor blockers for 24-hour blood pressure control: meta-analysis of a clinical database. J Clin Hypertens 2003; 1 $58-63$

5 Kontny F, Risanger T, Bye A, Arnesen $\varnothing$, Johansen OE. TELMIMORE Study Investigators. Effects of telmisartan on office and 24-hour ambulatory blood pressure: an observational study in hypertensive patients managed in primary care. Vasc Health Risk Manag 2010; 6: 31-38.

6 Haria M, Wagstaff AJ. Amlodipine. A reappraisal of its pharmacological properties and therapeutic use in cardiovascular disease. Drugs 1995; 50: 560-586.

7 Dahlöf B, Sever PS, Poulter NR, Wedel H, Beevers DG, Caulfield M, Collins R, Kjeldsen SE, Kristinsson A, McInnes GT, Mehlsen J, Nieminen M, O'Brien E, Ostergren
JASCOT Investigators. Prevention of cardiovascular events with an antihypertensive regimen of amlodipine adding perindopril as required versus atenolol adding bendroflumethiazide as required, in the Anglo-Scandinavian Cardiac Outcomes Trial-Blood Pressure Lowering Arm (ASCOT-BPLA): a multicentre randomised controlled trial. Lancet 2005; 366: 895-906.

8 Jamerson K, Weber MA, Bakris GL, Dahlöf B, Pitt B, Shi V, Hester A, Gupte J, Gatlin M, Velazquez EJ. ACCOMPLISH Trial Investigators. Benazepril plus amlodipine or hydrochlorothiazide for hypertension in high-risk patients. N Engl J Med 2008; 359: 2417-2428.

9 Bangalore S, Kamalakkannan G, Parkar S, Messerli FH. Fixed-dose combinations improve medication compliance: a meta-analysis. Am J Med 2007; 120: 713-719.

10 Gupta AK, Arshad S, Poulter NR. Compliance, safety, and effectiveness of fixed-dose combinations of antihypertensive agents: a meta-analysis. Hypertension 2010; 55: 399-407.

11 Neldam S, Lang M, Jones RTEAMSTA-5 Investigators. Telmisartan and amlodipine single-pill combinations vs amlodipine monotherapy for superior blood pressure lowering and improved tolerability in patients with uncontrolled hypertension: results of the TEAMSTA-5 study. J Clin Hypertens 2011; 13: 459-466.

12 Hermida RC, Ayala DE, Fernández JR, Calvo C. Comparison of the efficacy of morning versus evening administration of telmisartan in essential hypertension. Hypertension 2007; 50: 715-722.

13 O'Brien E, Asmar R, Beilin L, Imai Y, Mancia G, Mengden T, Myers M, Padfield P, Palatini P, Parati G, Pickering T, Redon J, Staessen J, Stergiou G, Verdecchia PEuropean Society of Hypertension Working Group on Blood Pressure Monitoring. Practice guidelines of the European Society of Hypertension for clinic, ambulatory and self blood pressure measurement. J Hypertens 2005; 23: 697-701.

14 Matsuo S, Imai E, Horio M, Yasuda Y, Tomita K, Nitta K, Yamagata K, Tomino Y, Yokoyama $\mathrm{H}$, Hishida $\mathrm{A}$. Revised equations for estimated GFR from serum creatinine in Japan. Am J Kidney Dis 2009; 53: 982-992.

15 Teramoto T, Sasaki J, Ueshima H, Egusa G, Kinoshita M, Shimamoto K, Daida H, Biro S, Hirobe K, Funahashi T, Yokote K, Yokode M. Metabolic syndrome. J Atheroscler Thromb. 2008; 15: 1-5.

16 Mengden T, Binswanger B, Spühler T, Weisser B, Vetter W. The use of self-measured blood pressure determinations in assessing dynamics of drug compliance in a study with amlodipine once a day, morning versus evening. J Hypertens 1993; 11 . 1403-1411.

17 Chavanu K, Merkel J, Quan AM. Role of ambulatory blood pressure monitoring in the management of hypertension. Am J Health Syst Pharm 2008; 65: 209-218.

18 Clement DL, De Buyzere ML, De Bacquer DA, de Leeuw PW, Duprez DA, Fagard RH Gheeraert PJ, Missault LH, Braun JJ, Six RO, Van Der Niepen P, O'Brien EOffice versus Ambulatory Pressure Study Investigators. Prognostic value of ambulatory blood-pressure recordings in patients with treated hypertension. $N$ Engl J Med 2003; 348: 2407-2415.

19 Lewington S, Clarke R, Qizilbash N, Peto R, Collins R. Age-specific relevance of usual blood pressure to vascular mortality: a meta-analysis of individual data for one million adults in 61 prospective studies. Lancet 2002; 360: 1903-1913.

20 Dolan E, Stanton A, Thijs L, Hinedi K, Atkins N, McClory S, Den Hond E, McCormack $P$, Staessen JA, O'Brien E. Superiority of ambulatory over clinic blood pressure measurement in predicting mortality: the Dublin outcome study. Hypertension 2005; 46: $156-161$

21 de la Sierra A, Banegas JR, Segura J, Gorostidi M, Ruilope LMCARDIORISC Event Investigators. Ambulatory blood pressure monitoring and development of cardiovascular events in high-risk patients included in the Spanish ABPM registry: the CARDIORISC Event study. J Hypertens 2012; 30: 713-719.

22 Cuspidi C, Sala C, Valerio C, Negri F, Mancia G. Nocturnal blood pressure in untreated essential hypertensives. Blood Press 2011; 20: 335-341.

23 Pierdomenico SD, Cuccurullo F. Ambulatory blood pressure monitoring in type 2 diabetes and metabolic syndrome: a review. Blood Press Monit 2010; 15: 1-7.

24 Battershill AJ, Scott LJ. Telmisartan: a review of its use in the management of hypertension. Drugs 2006; 66: 51-83.

25 Inoue T, Node K. Telmisartan as a metabolic sartan for targeting vascular failure. Expert Opin Pharmacother 2008; 9: 1397-1406.

26 Lindqvist M, Kahan T, Melcher A, Ekholm M, Hjemdahl P. Long-term calcium antagonist treatment of human hypertension with mibefradil or amlodipine increases sympathetic nerve activity. J Hypertens 2007; 25: 169-175.

27 Karas M, Lacourcière $Y$, LeBlanc AR, Nadeau R, Dubé B, Florescu M, Lamarre-Cliche $M$, Poirier L, Larochelle $P$, de Champlain J. Effect of the renin-angiotensin system or calcium channel blockade on the circadian variation of heart rate variability, blood pressure and circulating catecholamines in hypertensive patients. J Hypertens 2005; 23: $1251-1260$.

28 Goodfriend TL, Elliott ME, Catt KJ. Angiotensin receptors and their antagonists. N Eng/ J Med 1996; 334: 1649-1654.

29 Burnier M. Angiotensin II type 1 receptor blockers. Circulation 2001; 103 904-912.

30 Uresin Y, Erbas B, Ozek M, Ozkök E, Gürol AO. Losartan may prevent the elevation of plasma glucose, corticosterone and catecholamine levels induced by chronic stress. $\mathrm{J}$ Renin Angiotensin Aldosterone Syst 2004; 5: 93-96. 